potential sources is daunting, as are the limitations inherent in each category of document that records reading and implies reader response. Recognizing the weaknesses of individual sources, the author relies on a massive assemblage of diverse material that in the aggregate is more illustrative than its individual parts. At the same time, there is heavy reliance on single texts or artistic images as representative of various categories. Nine of the ten chapters begin, for example, with either a textual example or a historical moment that is used to suggest a broad theme. Among the sources considered are artistic depictions-the subject of an entire chapter-and records of reading experience as noted in novels, diaries, memoirs, correspondence, and critical reviews. Probably the most significant source is one that has never been thoroughly examined: the large collections of fan letters sent to members of the Académie française and to other authors who saved a large amount of their mail. Although a problematic source, partly due to the selective nature of these collections and patterns of flattery, the letters are especially amenable to Allen's line of investigation. He selects 1,450 letters sent to ten major authors: Mme. de Stael, Stendhal, Balzac, Baudelaire, Sue, Flaubert, Michelet, the Goncourts, Zola, and Anatole France. Sue, Michelet, and France receive the most attention, mainly because of the wide response aroused by the controversial works they published.

The range of sources, although enormous, is definitely weighted toward higher culture. There is some attention to more mundane publications, such as newspapers and schoolbooks, but only peripheral consideration of the printed word in the life of less active readers, those whose reading included almanacs, accounting guides, manuals, prayer books, or popular literature. Because selection of sources is so crucial to further research on this topic, it is a pity that Allen's book could not contain a full bibliography to bring together the entire range of material used. Even with the voluminous footnotes, generally well-explained ta- bles, and a selected bibliography of archival sources, it would have been helpful for scholars to have the same type of topical bibliography as Allen was able to include in his first book, Popular French Romanticism: Authors, Readers, and Books in the 19th Century.

The book is strongest in its distillation of disparate historical sources on printing and reading and in the way it offers an impetus for further investigation of all areas of reading. It opens the possibility of mining additional sources for studies on modern France that could be patterned after the work Roger Chartier and Robert Darnton have done on the early modern period, and it gives direction to future scholarship in the area of reading culture, including café society, discussion clubs, bookstore development, and other aspects of the literary scene. If, by the nature of its sources, this work often has to be more impressionistic than empirical, the conclusion seems reasonable throughout. Clearly, this study contributes significantly to the history of reading.-Mary Jane Parrine, Stanford University, Stanford, California.

Reich, Robert B. The Work of Nations: Preparing Ourselves for 21st-Century Capitalism. New York: Knopf, 1991. 331p. \$24 (ISBN 0-394-58352-3).

In his latest book, The Work of Nations: Preparing Ourselves for 21st-Century Capitalism, Robert B. Reich, political economist at Harvard's John F. Kennedy School of Government takes issue with the statement made by President Bush in his 1989 inaugural address: "We have more will than wallet, but will is what we need." Reich believes "We have the wallet, but do we have the will?" is the real question that Bush should pose to the American public. Deliberately, persuasively, harshly, Reich informs the reader how old definitions of economic nationalism no longer pertain, how new work patterns in "global webs" remove us from daily national social problems, and why we need to recognize that "our mutual obligations as citizens extend beyond our economic usefulness to one another, and act accordingly." 
In the first two sections of his book, Reich describes the demise of America's core corporations and how the global web of enterprise has transformed the way in which businesses operate. Increasingly these businesses link specialized needs with customized solutions, emphasizing services over goods by means of international partnerships that exploit the problem-solving abilities of skilled people, while contracting with unskilled laborers in low-wage countries for "whatever must be standardized and produced in high volume." The concept of centralized ownership and control, says Reich, where corporations operate as hierarchical entities, is misleading. Instead, ownership and control are frequently diffused, and the main value of the enterprise derives from the "problem-solving, -identifying, and -brokering skills of key people." The "nationality" of a corporation is often irrelevant. Of more importance to our economy is the extent to which an enterprise-irrespective of its national origin-values the skills of American workers and contributes to their material and social well-being.

In the last two sections of the bookand here lies some worthwhile reading for members of our profession-Reich identifies three main job categories of the future and redefines the meaning and "work" of a nation. Traditional classifications of America's "major occupational groups," such as managerial and professional specialty; technical, sales, and administrative support; and operator, fabricator, and laborer, are by this time outmoded. Reich proposes three new categories to represent "the three different competitive positions in which Americans find themselves"routine production services, in-person services, and symbolic-analytic services. The first category encompasses people who perform repetitive tasks, including many routine supervisory jobs that require "repetitive checks on subordinates' work and the enforcement of standard operating procedures." Reich calculates that in 1990 routine production services accounted for about $25 \%$ of American jobs and that their numbers are declining. The second category, inperson services, comprises about $30 \%$ of the jobs in America, and its numbers are growing. In-person servers, as opposed to routine producers, are "in direct contact with the ultimate beneficiaries of their work." Finally, symbolic-analytic services encompass the intangible processes of problem identification, problem solving, and information brokering. This work sector is transforming the way business is conducted; it is also the most competitive category and least vulnerable to usurpation in the global economy. According to Reich, these three categories make up $75 \%$ of American jobs.

The economic plight of routine producers in the United States is worsening because their skills can be replicated less expensively abroad. Meanwhile, the standard of living of in-person servers is tied to the desires and prosperity of the symbolic analysts on whom their livelihood depends. The increasing disparity in the standard of living between the symbolic analysts and the other two major work categories has segregated Americans by income residentially, socially, and educationally. Reich repeatedly reminds the reader that one-fifth of our citizens enjoy nearly $50 \%$ of the national income.

And now we return to the "will-versus-wallet" question: Reich contends that we can afford to invest more money in infrastructure, education, and training if we can find the political will to implement solutions that would require-among other efforts-the top one-fifth of the earners to bear a greater share of the cost. Taking a somewhat cynical and admittedly "less charitable" view, however, Reich explains why it is likely that we will continue to travel in the hazardous direction of economic disparity. Hanging in the balance is not merely our economic viability, but our social cohesion as a nation. Reich's book is intended for a large, national public and has been widely reviewed. Although one might criticize the absence of a deeper historical perspective, quarrel with his nomenclature, or lament the paucity of solutions, Reich is persuasive, 
nonetheless, in arguing that the prevailing economic and social philosophy of "laissez cosmopolitanism" is dangerous. His fundamental questions, "Are we still a society, even if we are no longer an economy? Are we bound together by something more than the gross national product?" are difficult to ignore.

What is of significance here to librarians? First of all, through his descriptions of work classifications, Reich offers a framework by which to analyze our profession. We will readily find examples of routine producers-copy catalogers, data entry clerks, middle managers who review the accuracy of our daily procedures. We know, too, that this category of workers has diminished and that their duties have changed with increased automation. Many among us will perceive ourselves as in-person servers, meeting our patrons' daily requests through reference work, collection development, and bibliographic instruction. Finally, more and more of us may perceive our work as symbolic-analytic servicewhere we identify and solve information problems or broker our services in a global market. And even if we ourselves do not operate in the entrepreneurial global web, increasingly we may expect that the clientele we serve either aspires to or does. We can anticipate greater demands to customize, package, and tailor our services to match the particular needs of individuals in this group. We might also anticipate their willingness to pay for this service or to gain access to information sources without our intervention. These trends, which are by no means new, will continue to present strategic dilemmas for a profession based on democratic traditions of free and undifferentiated access. It may also contribute to splintering librarians further, as we segregate ourselves and our professional principles according to the clientele we serve. Academic, research, and special librarians may expect wellfunded symbolic analysts to figure prominently among their patrons, but most public and school librarians (certainly urban) will continue to serve the less fortunate $80 \%$. How we resolve and balance these demands within the profession is a microcosm of challenges presented to society as a whole. Reading Reich's book gives us reason to pause and re-boot, as we log on to the next century.-Martha L. Brogan, Yale University, New Haven, Connecticut.

\section{Reference and Information Services: An} Introduction. Ed. by Richard E. Bopp and Linda C. Smith. Englewood, Colo.: Libraries Unlimited, 1991. 483p. $\$ 47.50$ (ISBN 0-87287-875-9); paper, \$30 (ISBN 0-87287-788-4). LC 91-14086.

Richard Bopp and Linda Smith have created this volume in response to the perceived need for an integrated text to be used primarily by library and information science educators teaching basic reference courses. It is designed to provide an "overview both of the concepts and processes behind today's reference services and of the most important sources consulted in general reference work." On the whole they have succeeded, and this text is likely to replace William A. Katz's Introduction to Reference Work as the most popular text for beginning reference courses.

The work is arranged in twenty chapters written by twenty-one authors, most of them affiliated in some way with the University of Illinois at Urbana-Champaign. The twenty chapters are divided into two parts. Part 1, "Concepts and Processes," covers topics such as reference service philosophy, the reference interview, bibliographic control, electronic reference services, instruction, and evaluation. Part 2, "Information Sources and Their Use," includes an introductory chapter on the selection and evaluation of sources, and discussions of reference sources by type (such as directories, indexes and abstracts, and dictionaries).

The format for each chapter includes a list of sources and additional readings. The chapters dealing with sources also include a section called "search strategies." The chapters are current, and many 1990 and 1991 sources are cited. The suggestions for additional readings are helpful for the student who may wish to pursue a particular topic. Sample pages 